\title{
Sociedade e Multiculturalismo: Uma reflexão a luz da Lei de Diretrizes e Bases da Educação Nacional (LDB)
}

\author{
Society and Multiculturalism: A reflection to the light of the National Education of \\ Guidelines and Bases Law (LDB)
}

Sociedad y Multiculturalismo: Una reflexión a la luz de la Ley de Directrices y Base de la Educación Nacional (LDB)

Graciete Barros Silva ${ }^{1 *}$, Janaene Leandro de Sousa².

\begin{abstract}
RESUMO
Objetivos: Compreender como as instituições escolares trabalham com a educação multicultural na atual conjuntura social e política, destacando os conflitos situados na nossa sociedade que estão relacionados ao conhecimento da multicultura. Métodos: Trata-se de um estudo de abordagem qualitativa, como técnica de coleta de dados usou-se a pesquisa bibliográfica. Resultados: Vivemos em um mundo que ainda predomina 0 pensamento homogêneo (cultura única), intolerante a diversidades e a existência de diferentes grupos étnicos. Considerações finais: Torna-se necessário uma análise desses sistemas educativos para que se possa alcançar o que está previsto na Lei de Diretrizes e Bases da Educação Nacional 9394/96, que define regularizar o sistema de educação com base na constituição com o objetivo de tornar a educação para todos, construindo assim uma relação recíproca entre os indivíduos, relações estas que produziram mudanças e reforçará a identidade de cada individuo.
\end{abstract}

Palavras-chave: Multiculturalismo, Sociedade, Educação

\begin{abstract}
Objectives: To understand how school institutions work with multicultural education in the current social and political conjuncture, highlighting the conflicts in our society, that are related to multicultural knowledge. Methods: This is a qualitative approach, as data collection, was used bibliographical research. Results: We live in a world that still dominate the homogeneous thinking (unique culture), intolerant of diversity and the existence of different ethnic groups. Final considerations: It is necessary to analyze these educational systems in order to achieve what is provided in the National Education Guidelines and Bases Law 9894/96, which defines regularizing the education system based on the constitution with the aim of making education for all, thus building a reciprocal relationship between individuals, relations that have produced changes and reinforce the identity of each individual.
\end{abstract}

Keywords: Multiculturalism, Society, Education.

\section{RESUMEN}

Objetivos: Comprender cómo las instituciones escolares trabajan con la educación multicultural en la actual coyuntura social y política, destacando los conflictos situados en nuestra sociedad que están relacionados al conocimiento de la multicultura. Métodos: Se trata de un estudio de abordaje cualitativo, como técnica de recolección de datos se utilizó la investigación bibliográfica. Resultados: Vivimos en un mundo que aún predomina el pensamiento homogéneo (cultura única), intolerante a diversidades y la existencia de diferentes grupos étnicos. Consideraciones finales: Se hace necesario un análisis de estos sistemas educativos para que se pueda alcanzar lo que está previsto en la Ley de Directrices y Bases de la Educación Nacional 9394/96, que define regularizar el sistema de educación basado en la constitución con el objetivo de hacer la educación para todos, construyendo así una relación recíproca entre los individuos, relaciones éstas que produjeron cambios y reforzará la identidad de cada individuo.

Palabras clave: Multiculturalismo, Sociedad, Educación.

${ }^{1}$ Mestranda do Programa de Pós-Graduação em Educação da Universidade Estadual de Roraima em associação com o Instituto Federal de Educação. Boa Vista -Roraima. *E-mail: sgraciete.barros@gmail.com 


\section{INTRODUÇÃO}

O presente artigo tem como problemática discutir como as instituições escolares trabalham com a educação multicultural na atual conjuntura social e politica a luz da Lei de Diretrizes e Bases da Educação Nacional (LDB), visto que, a sociedade é formada por diferentes grupos sociais e culturais, dai a necessidade de se trabalhar nas instituições escolares com uma educação diferenciada que valorize as múltiplas culturas que encontram-se nestes espaços. Diante disso, diz que o termo multiculturalismo diz respeito a uma sociedade formada por uma diversidade de culturas ou subculturas vivendo e interagindo num mesmo espaço (CANEN A, 2000).

Assim sendo, as instituições escolares desempenham um papel fundamental na conquista de uma sociedade mais justa e, sobretudo democrática, portanto, uma educação multicultural reconhece que não vivemos num mundo homogêneo e admitir que existem diferentes grupos sociais dividindo um mesmo espaço, logo, podemos dizer que o multiculturalismo não é mistura, mas o reconhecimento das diferenças e ponto de partida para a convivência entre todos os sujeitos plurais. Um desafio que abre possibilidades de práticas curriculares e de formação docente numa perspectiva de construção de identidade comprometida com o ensino-aprendizagem multicultural (CANEN A, 2000).

Moreira AFB, Candau VM, 2008) diz que pensar na sociedade atualmente tendo em vista perspectivas multiculturais pressupõem contrapor ideias á logica do Estado Nacional , principalmente no que diz respeito a cultura, considerando o que se tem negado no decorrer da história, e partir deste viés reconstruir a interpretação dessa realidade, nascendo assim, uma pratica social educativa que privilegie a diversidade cultural.

Assim, no primeiro momento este artigo vai tratar de sociedade, multiculturalismo e educação tendo como embasamento, onde a sociedade multicultural pode ser constituída por um estado unicamente laico que defina e garanta o princípio básico da democracia: a pluralidade e a diversidade. Isso não significa afirmar que será uma sociedade quebrada ou dividida por grupos culturais ou étnicos, mas implica num processo de revigoramento onde os indivíduos possam lutar por seus direitos em busca de uma democratização tanto nos meios sociais quanto culturais (TAURAINE A, 1995).

Em um segundo momento o mesmo vai fazer uma pequena analise da atual politica educacional tendo como alicerce a LDB (Leis de Diretrizes e Bases da Educação Nacional) mostrando os limites e possibilidades em relação à educação multicultural, ou seja, o sistema educacional tem que prestar atenção aos níveis de intolerância que se pode chegar a causar, por isso não podem ocultar as crenças, culturas costumes de grupos coletivos, cujos membros têm direito de conviver em qualquer lugar independente de raça, cor, etnia e sexo (MOREIRA AFB, CANDAU VM, 2013).

Num terceiro momento faremos uma reflexão de como está a educação na sociedade multicultural roraimense, já que o estado de Roraima é habitado por diferentes grupos sociais e culturais e nas instituições de ensino não é diferente, portanto, objetivo deste estudo é compreender como as instituições escolares trabalham com a educação multicultural na atual conjuntura social e política. Diante disso, ressaltaremos se as escolas oferecem subsídios para a elaboração de programas de educação escolar que atenda os interesses dos estudantes, considerando os princípios da pluralidade cultural.

\section{MÉTODOS}

O estudo em questão é de natureza qualitativa que vai tratar de compreender como as instituições escolares trabalham com a educação multicultural, tendo como auxílio a Lei de diretrizes e Bases da Educação Nacional-LDB, este tipo de pesquisa não se preocupa com representatividade numérica, mas sim com o aprofundamento da compreensão de questões sociais.

Assim sendo, como técnica de coleta de dados usou-se a pesquisa bibliográfica que é uma estratégia que busca explicar um problema por meio de estudos, teorias, descobertas, divulgados em diferentes fontes: 
livros, revistas, artigos, enciclopédias, veículos eletrônicos de informações, etc. A utilização dessa estratégia de pesquisa consiste no conhecimento e análise de um conjunto de contribuições científicas e teóricas acerca de um tema que desejamos compreender.

Portanto, a pesquisa bibliográfica foi essencial para a elaboração desse estudo, obtendo informações que estejam de acordo com os objetivos delimitados inicialmente, através de autores que abordam a educação multicultural.

\section{RESULTADOS E DISCUSSÕES}

Através deste estudo buscamos fazer uma reflexão da sociedade em relação a educação e ao multiculturalismo discutido como as instituições escolares trabalham com a educação multicultural na atual conjuntura social e politica fazendo alusão quando necessário com a Lei de Diretrizes e Bases da Educação Nacional -LDB, onde a referente busca legitimar o sistema educacional tendo como artifício a Constituição Federal, almejando que o multiculturalismo se torne uma forma de política social reconhecendo os grupos "minoritários" que sempre foram excluídos da sociedade seja por condições históricas , raciais dentre outras, respeitando sempre a alteridade do outro.

Neste sentido, pensar na sociedade brasileira como sendo multicultural pressupõe ponderar que a referente é constituída sob base da democracia que avalia a participação de todos os grupos os grupos sociais e culturais que compõe a nação. Assim, como os autores Moreira AFB, Candau VM (2008) dizem que o multiculturalismo é um movimento que envolve um tipo de consciência coletiva, lutando em prol dos seus direitos e contra qualquer forma de ceticismo e se afirma na diversidade e nas diferenças culturais.

Nesta conjuntura uma educação multicultural tem como finalidade a valorização de todas as manifestações culturais presente na sociedade, preparando os educandos para viverem em uma sociedade onde a diversidade cultural se legitima, abrindo espaços para uma politica intercultural que reconhece e aceita o pluralismo cultural como um fator social com vista numa sociedade democrática e de direitos (MOREIRA AFB, CANDAU VM, 2008).

\section{Sociedade, multiculturalismo e educação}

Em sociologia, uma sociedade significa "associações amistosas com outros" isto é, um conjunto de pessoas que compartilham propósitos, gostos, que interagem entre se formando uma comunidade. A sociedade é um objeto de estudo das ciências sociais. O sociólogo francês Alain Touraine foi um dos poucos pensadores contemporâneos que pensara em sociedade nos contextos sociais tendo como parâmetros a democracia da América Latina. As suas obras demonstram estímulos não somente teóricos ou de caráteres analíticos, mas também demonstram preocupações com as distintas dinâmicas históricas e culturais das complexas sociedades latino-Americana (GADEA CA, SCHERER WARREN I, 2005).

Gadea CA e Scherer WI (2005), nos adverte que debater as hipóteses de Touraine A (1995), poderia conduzir-nos a confrontar a diversa gama de contribuições do sociólogo com outros clássicos como Habermas, porém o presente artigo insere um discursão na qual coloca frente a pensadores contemporâneos, restabelecendo uma relação frente às contribuições sintéticas acerca da sociedade.

Falar em sociedades plurais adverte pensar no reconhecimento da diversidade cultural, religiosa e étnica. Todavia como destaca Touraine A (1995), que a sociedade multicultural não é uma fragmentação da sociedade em si mesma, mas uma combinação de pluralidades, intercâmbios e comunicações que se expressam mediante suas culturas. Portanto, temos que considerar que a tendência da sociedade atualmente é universalização e a globalização não somente da economia, mas, sobretudo da da cultura. Assim, os diferentes grupos sociais vêm se fortalecendo por meio dos progressos da tecnologia e dos movimentos sociais, lutando pela preservação de sua identidade. Sob este ponto de vista ressalta que a sociedade multicultural pode ser constituída por um estado exclusivamente laico, que defenda e garanta o princípio básico a democracia, a pluralidade e a diversidade. 
Contudo, isso não significa que esta sociedade será fragmentada por grupos étnicos ou culturais, mas implica reafirmar que esse processo de refinamento dos sujeitos revigora os direitos estruturais. Sendo assim, a ideia de democracia não se consolida unicamente por um conjunto de garantias formais e institucionais e formais, mas principalmente nas lutas dos indivíduos por sua cultura e por sua liberdade (TAURAINE A, 1995).

Neste contexto, é necessário preparar os indivíduos para o convívio social, sobretudo, para o convívio com outras culturas, respeitando a alteridade de cada individuo. E, portanto, torna-se imprescindível valorizar o pluralismo cultural existente em nossas sociedades, almejando a harmonia entre os universalismos produzidos pela modernidade garantindo a igualdade direito e oportunidade a todos (MACHADO CG, 2002).

\section{A LDB e a educação multicultural: limites e possibilidades}

A educação multicultural aparece como reação ao monolitismo cultural onde a defesa da multiculturalidade assume ponto de partida nos territórios habitados por diferentes raças e etnias titulares de uma rica herança cultural que há que respeitar, manter e promover o outro onde não existem ninguém melhor ou pior todos será igual perante a sociedade esta filosofia está na base das propostas da educação multicultural. A mesma é, como outras, uma fração do modo de vida dos grupos sociais que a criam e recriam, entre outros inventos da cultura em sociedade.

A Lei de Diretrizes e Bases da Educação Nacional define regularizar o sistema de educação com bases na constituição, que foi citada pela primeira vez na constituição de 1934. A primeira LDB foi criada em 1961, seguida por uma versão em 1971, que revigorou até a mais recente 1996 (MONTEIRO RA, GONZÁLEZ LM, GARCIA AB, 2011).

A atual LDB foi criada por Fernando Henrique Cardoso, e pelo ministro da educação Paulo Renato em dezembro de 1996, com o objetivo de tornar a educação para todos, partindo da premissa do Art. $1^{\circ}$ que trata da abrangência do processo formativo que se desenvolve na vida familiar, na sociedade e nas manifestações culturais. A ideia do plano no âmbito educacional remota na década de 1930, provavelmente a sua primeira manifestação explicita nos é dada pelo "Manifesto dos pioneiros da educação nova", que trata os trabalhos científicos como uma janela para a ampliação dos estudos científicos e resolução dos problemas educacionais por meio da força das ideias críticas e combate à negação da emancipação humana (MONTEIRO RA , GONZÁLEZ LM, GARCIA AB, 2011).

Esse contrato influenciou, por certo, a Constituição Brasileira de 1934, cujo artigo 150, alínea a educação, fixando o plano nacional de educação, tolerante ao ensino de todos os graus e ramos, comuns e especializados. Se a diversidade cultural é uma valiosa herança, a instituição escolar tem que fornecer para a manter a mesma, sendo necessário englobar esta pluralidade cultural nos conteúdos curriculares nas escolas (MONTEIRO RA, GONZÁLEZ LM, GARCIA AB, 2011).

A educação multicultural pode formar utensílios para a superação das diferenças. No espaço contemporâneo as relações sociais são distribuídas num campo social para alcançar as necessidades da humanidade, pois as diferenças existem e precisam serem conhecidas a partir da mudança de atitude de cada sujeito envolvido no processo de ensino e aprendizagem, de modo que este seja um processo de reconhecimento não só de práticas sociais, mas sobretudo da importância das diferentes culturas existentes na nossa sociedade e no mundo (MOREIRA AFB, CANDAU VM , 2008).

Segundo, Moreira AFB, Candau VM (2008), o multiculturalismo tem tudo a ver com os processos educacionais, porque desenvolvem não somente metodologias educacionais, excludentes, mas, sobretudo porque faz surgir movimentos em busca de uma educação para a cidadania, onde a luta contra as memórias lidera o pensamento político. O artigo 206 da Constituição Federal, no item IV inclui como princípio básico o "respeito a liberdade e apreço a tolerância" e o Inciso X, que adiciona o começo da "valorização da experiência extraescolar".

Eles reforçam o apoio ao pluralismo cultural, mencionando a necessidade de incluir o respeito as crenças e costumes de todas as culturas, melhorando o carretar democrático do processo educativo, dando ênfase a tolerância a diferença, ou seja, o papel do educador é conversar com seus educados afim de construir 
métodos que proporcionam a compreensão da diversidade cultural, fazendo interpretação da realidade das diferenças existentes na sociedade. Cabe ao educador construir pontes solidas entre os fundamentos e a compreensão críticas dos fenômenos frente a abordagem curricular.

\section{Educação e sociedade multicultural roraimense}

O Estado de Roraima recentemente foi denominado no contexto multicultural, onde cabe advertir a altivez que faz entre multicultural e multiculturalismo; o primeiro é qualificado de sociedades que apresentam diferentes comunidades culturais originais que tenta levar uma vida comum ,já o segundo é como se fosse um substantivo que vai designa políticas e estratégias para conduzir os problemas gerados em sociedades multiculturais (HALL S, 2003).

No contexto multicultural roraimense devemos levar em conta o mito do eldorado do ouro e das pedras preciosas que são os principais encantos locais, responsável pela migração de pessoas de todo o Brasil para o então território. Diante dessa medite torna-se fácil entender como as escolas ocupam lugar central nas disputas multiculturais onde impõem valores que acabam fazendo parte da vida do indivíduo, visando uma batalha libertadora significativa, desenvolvendo o ato crítico de cada aluno, porém, atualmente não há mais possibilidade de pensar em sociedades isoladas que mantem sua cultura pura, pois estas sofrem transformação tecnológica, migratórias e sobretudo, por causa dos processos de globalização da economia ( FREITAS LAS, 2003). Nesse sentido acredita-se que a capital de Boa Vista Roraima constitui-se em um órgão de atração de culturas migrantes na qual dividem suas culturas locais, indígena e urbanas.

Freitas LAS, 2003, ressalta que a sociedade Roraimense pode ser considerada multicultural pois é habitada por diferentes povos e etnias, onde predomina a etnia indígena, estas foram discriminados e oprimidas durante muito tempo constituindo uma ofensa ao princípio da dignidade humana, razão a justificar o histórico das lutas sociais e conquistas destes povos. Atualmente os povos indígenas de Roraima lutam por sua participação plena na vida social, a fim de se desenvolver e manter sua cultura. A sociedade roraimense é um dos maiores exemplos de luta na busca da educação indígena é o estado de Roraima que teve suas primeiras escolas na década de 30 por iniciativa do SPI (serviço de proteção ao índio). Era uma educação estruturada pela igreja católica que prevaleceu até a década de 70 do século $\mathrm{XX}$, a partir de então a educação passa a ser responsabilidade do governo.

O ensino continuava muito precário e começa a ter grandes mudanças com o surgimento da OPIR (organização da educação indígena de Roraima) que tinha por objetivo consolidar as bases de uma política permanente de formação de professores e material didático diferenciado. Foram criados também o CIR (conselho indígena de Roraima) o APIR (associação dos povos indígenas de Roraima) o DEI (divisão de educação indígena) e o OMIR (organização das mulheres indígenas de Roraima) (FREITAS LAS, 2003).

A teoria do multiculturalismo contribui para o debate sobre as diferenças estabelecendo bases teóricas visando o reconhecimento e os direitos de cada um, onde é necessário aprender a conviver junto com o outro (MCLAREN P, 2000).

A Constituição (1988) abre um novo horizonte de possibilidades ao reconhecer os direitos coletivos e permanentes dos povos indígenas e, partindo dessa premissa os povos indígenas passam a serem reconhecidos também enquanto coletividade culturalmente distinta de uma sociedade pluriétnica e multicultural. Esta é a base de reconhecimento de direitos de uma sociedade que continua a existir como povos que são. Atualmente, pensando na preservação da cultura, a educação indígena está comtemplada no Plano Nacional de Educação-PNE, onde a Lei de Diretrizes e Bases da Educação Nacional- LDB 9.394/96, ao tratar da educação escolar indígena assegura no artigo 78 que os sistema de ensino desenvolverá programas para a oferta de uma educação escolar bilíngue e intercultural aos povos indígenas com o intuito de recuperar suas memorias históricas, valorizando suas línguas e ciências bem como a reafirmação de suas identidades.

Deste feito, a Lei de Diretrizes e Bases da Educação Nacional - LDB e o Plano Nacional de EducaçãoPLE têm abordado o direito dos povos indígenas a ter uma educação diferenciada e intercultural, mas o 
Estado de Roraima não tem subsídios para manter essa pauta de valorização as línguas dos grupos, pois o currículo adotado por ambos são dos não índios. Diante disso, o Ministério da Educação - MEC põe em disposição de cada profissional da educação indígena um exemplar, para que ambos possam ser utilizados como auxílios no trabalho diário. Contudo, adverte-se que uma recente pesquisa realizada pelo Sistema de Avaliação da Educação Básica (SAEB) comprovou que a educação no Estado de Roraima é uma das piores do Brasil, na qual $43,1 \%$ dos alunos analisados na $4^{\circ}$ serie em língua portuguesa estão em estágio crítico, ou seja são, leitores de nível primário.

\section{CONSIDERAÇÕES FINAIS}

Em suma, percebemos com este trabalho que há a necessidade de uma "nova visão" sobre a diversidade cultural, uma vez que essa atitude de reconhecimento das diferenças proporciona aos indivíduos um novo horizonte desmitificando preconceitos, vencendo as formas maléficas de etnocentrismo. Assim, tratar de questões relacionadas com as ideias e bandeiras defendidas pelo multiculturalismo se constitui um desafio que precisa ser vencido, haja visto que essa barreira ainda não foi derrotada e o corpo docente permanece sem a devida compreensão do seu verdadeiro papel no processo de formação de cidadãos conscientes e críticos. Sendo assim, um dos primeiros caminhos a ser percorrido é o do reconhecimento dos grupos tidos como inferiores dando a todos o direito de livre manifestação e expressão.

\section{REFERÊNCIAS}

1. BRASIL. Lei 11.645, de 10 de março de 2008. Altera a Lei no 9.394, de 20 de dezembro de 1996, modificada pela Lei no 10.639, de 9 de janeiro de 2003, que estabelece as diretrizes e bases da educação nacional, para incluir no currículo oficial da rede de ensino a obrigatoriedade da temática "História e Cultura Afro-Brasileira e Indígena".

2. Lei 9.394, de 20 de dezembro de 1996. Lei de Diretrizes e Bases de Educação Nacional. Brasília: MEC.1996.

3. Resolução oㅡ 01, de 17 de junho de 2004. Conselho Nacional de Educação/ Conselho Pleno.

4. Diretrizes Curriculares Nacionais para a Educação das Relações Étnico-Raciais. Brasília: MEC/SEF, 2004.

5. CANEN A. Educação multicultural, identidade nacional e pluralidade cultural: tensões e implicações curriculares. Publicado no Caderno de Pesquisa 111, p. 135-149, dezembro, 2000 -p. 135-149.

6. FREITAS LAS. Intercultura e Educação. Revista Brasileira de Educação. Santa Catarina, n.23, maio/junho. /jul./ago,2003.

7. GADEA CA, SCHERER-WARREN I. Alain Touraine e a democracia na América Latina. Cadernos do CEAS, Salvador, n. 220, p. 9-18, nov.-dez. (2005).

8. HALL S. A centralidade da cultura: notas sobre as revoluções culturais de nosso tempo. Educação \& realidade, v.22, n.2, p.15-46. 2003.

9. MACHADO CG. Multiculturalismo: muito além da riqueza e da diferença. Rio de Janeiro: DP\&A, 2002.

10. MONTEIRO RA, GONZÁLEZ LM, GARCIA AB. Lei de Diretrizes e Bases da Educação Nacional: o porquê e seu contexto histórico. Revista Eletrônica de Educação - UFSCar, v.5, n.2, p. 82 - 95, jun./dez. 2011

11. MOREIRA, AFB, CANDAU, VM. (2003) Educação escolar e cultura(s): construindo caminhos. In: Revista Brasileira de Educação, n. 23, p. 156-168.

12. Multiculturalismo: diferenças culturais e práticas pedagógicas. 4 ed. Petrópolis, RJ:Vozes,2018.

13. MCLAREN P. Multiculturalismo Crítico. São paulo: Cortez, Instituto Paulo Freire, 2000.

14. A vida nas escolas: uma introdução à Pedagogia crítica nos fundamentos da Educação. Porto Alegre: Artes Médicas, 1997.

15. MINAYO MC. O desafio do conhecimento: Pesquisa Qualitativa em Saúde. 12a ed. São Paulo: Hucitec-Abrasco, 2010.

16. TOURAINE A. Iguais e Diferentes poderemos viver juntos? Buenos Aires: Fondo de cultura Econômica, 1994.Crítica da modernidade. Petrópolis :Vozes. 1997.

17. RIBEIRO D. O povo Brasileiro: A Formação e o Sentido do Brasil. SP. $2^{\circ}$ Ed. CIA das Letras, 1995. 